\title{
Boundaries of Distance. Local Media Relevance for Citizens: Measuring Consumption, Digital Extensions and Information Levels
}

\author{
Fábio Ribeiro 1,2* \\ (iD) 0000-0001-8071-6145 SC 57204005993
}

Luís Bonixe ${ }^{3 * *}$

(iD) 0000-0003-1288-7529 SC 57214687319

${ }^{1}$ University of Trás-os-Montes e Alto Douro (UTAD), Communication and Society Research Centre, PORTUGAL

2 University of Minho (UM), PORTUGAL

${ }^{3}$ Polytechnic Institute of Portalegre, ICNOVA, PORTUGAL

*Corresponding author: fabior@utad.pt

${ }^{* *}$ Corresponding author: luisbonixe@ipportalegre.pt

Citation: Ribeiro, F., \& Bonixe, L. (2021). Boundaries of Distance. Local Media Relevance for Citizens: Measuring Consumption, Digital Extensions and Information Levels. Online Journal of Communication and Media Technologies, 11(1), e2021xx. https://doi.org/10.30935/ojcmt/11108

\section{ARTICLE INFO}

Received: 12 Jan 2021

Accepted: 7 Jun 2021

\section{ABSTRACT}

Local media are decisive for communities in the context of a global culture. In Portugal, communicating for a more geographically restricted area deals with permanent hazards, especially in the journalistic scope, from both structural and organizational points of view. Arguably weakened and lacking from institutional support, Portuguese local media, ranging from printed media, radio, and television to online broadcasts, still thrive on uncertainty. Also, from an academic point view, little is known about the audiences' perceptions towards these local media. In doing so, this article presents the data collected from an online survey of 139 consumers of local media, thus concluding: traditional media (printed and FM) are still the most consumed formats, compared to the online scope; the COVID-19 pandemic was not decisive to increase local media consumption habits; seeking for information is the fundamental reason to follow local media; participants understand that websites and Facebook, mainly, are the most dynamic digital spaces that local media foster, thus giving them a very good evaluation; half of the sample have already interacted with broadcasters, especially to suggest ideas for journalistic approaches; in a global perspective, participants are pleased with the news coverage of local media towards local matters. Future research should implement complementary scientific approaches, based on in-depth perspectives to fully understand motivations to engage with local media and other social representations towards these mass media.

Keywords: local media, audiences, relevance, digital, consumption, information

\section{BACKGROUND AND CONTEXT: LOCAL MEDIA IN PORTUGAL}

Local media is, by definition, associated with a discourse linked to the communities where it is included, as it is seen as a fundamental actor for the knowledge and construction of a public debate on relevant issues of the localities. The local is seen as the environment in which socialization and interaction processes take place generating social bonds and networks among neighbours and in this scenario, local media represent a symbolic space that creates a local identity that is born from the sharing of common interests and from an own way of relationship (Garcia, 2012) and contributes to alternative interpretations to the national media (Castells, 2003). 
Local media contribute, in this way, to affirm the communities where they are inserted in a global culture, constituting a sounding board of the territory in its different dimensions: cultural, political, social and serving as a stage for confrontation and debate on public issues.

In this sense, the connection of the press and the local radios to the territory is fundamental and is one of the main arguments as a distinctive factor of its specificity because it allows the knowledge and the debate about local issues, in particular in more isolated regions (Cardoso et al., 2018b; Jerónimo et al., 2020).

Despite the social, cultural, and political importance that is recognized to local media, we identify in Portugal a sector with strong weaknesses and constraints from the structural and organizational point of view (Carvalho et al., 2010).

Regarding the local press, the report prepared by the Communication Observatory refers to the business diversity having verified the existence of a scenario "with publications that resist well to the mutability of a sector in crisis, and others that only survive because they are benefiting from the altruism and resilience of their players who declare love for the publication as an extension of the love they feel for their lands" (Cardoso et al., 2018b, p. 79).

This scenario was, in several aspects, affected by the pandemic situation of the last year and a half. Effectively, this aspect could not fail to have effects on a sector that already had serious organizational and financial problems. The professional and regulatory structures of the media in Portugal warned very early on about the crisis that would affect in particular the local Portuguese media. The Journalists' Union referred that it received "distressing reports of what is happening in the regional press" underlining that this scenario foresaw a context in which "hundreds or thousands of journalists were heading towards unemployment", in that sense the then president of the Union, Sofia Branco, warned that it was necessary to "urgently adopt other measures such as the reduction of the paid postage and the offer of online subscriptions of regional information organs" (Branco, 2020, May 20).

As such, the Portuguese Regulatory Authority for the Media (ERC), in a report aimed at understanding the impact of the pandemic on the media in Portugal, states that $29 \%$ of the companies that responded to the survey mentioned: "having suspended the print edition, with most having an online alternative" (ERC, 2020, p. 40). The same study mentions that $6 \%$ suspended the print edition without having any alternative, which in practice meant the temporary non-publication of the newspaper. On the other hand, indicates the same report, $4 \%$ of as of 90 publications, "indicated having changed the periodicity of the printed editions, spacing the output of the editions (e.g., weekly to fortnightly; monthly to bimonthly). Already three-fifths stated that they had decreased the number of pages of the print edition" (ERC, 2020, p. 41). Print distribution was affected by the closure of outlets during the lockdown, according to $81 \%$ of respondents. In contrast, "more than threefifths recorded an increase in their online audiences, which is a reflection of strategies to maintain editorial activity and capture readers" (ERC, 2020, p. 42). As a consequence, this scenario was reflected in the publications' revenues. According to the report, "it is estimated that $27 \%$ of local and regional press companies suffered a drop in revenue of between 61 and $80 \%$. A slice of 26\% registered decreases between 41 and $60 \%$, and another quarter between 21 and 40\% (ERC, 2020, p. 43).

In the radio sector, the context is not very optimistic either. The Portuguese local radio broadcasting is nowadays characterized by a huge diversity of projects, some of them calling into question the initial goals of this kind of radio. Contrary to what started to happen and what motivated the liberalization of the radio sector in Portugal in the second decade of the 21 st century, what we call Portuguese local radio stations is, in fact, a set of stations that can be divided into two major groups.

On the one hand, those that maintain the characteristics of a local radio station - with local news and local programming - and, on the other, those that despite broadcasting locally, opt for thematic programming, usually music and without any connection to the community. These radios are mainly located in the two large metropolitan areas of Lisbon and Porto.

In the aforementioned report by the ERC (2020) aimed at tracing the impact of the pandemic on the media, it is mentioned that "44\% of local radio operators reported revenue losses between 61 and $80 \%$ ", figures that refer to global revenues, with advertising being the most affected type of revenue in the context of local broadcasters. 
Data that is perceived by the local radio journalists themselves, who look at the future of this media with doubts and concerns. In a survey conducted with the aim of understanding the routines and constraints of Portuguese radio journalists in the pandemic (Bonixe, 2021) it was found that half of the respondents working in Portuguese local radio stations, fear for the future of their radio. Another finding in this study indicates that journalists from local radio stations consider that the lack of human resources was what most interfered with their work during the pandemic, a finding that reinforces previous studies that point to the chronic problems of Portuguese local broadcasters in relation to attracting professionals since $87 \%$ of Portuguese local broadcasting companies are micro-companies with a number of employees lower than 10 (Carvalho et al., 2010).

Despite these less positive scenarios for local media, in particular press and radio, the available data show a significant level of trust in Portuguese proximity media.

A recent Reuters Institute study in relation to Portugal (2021) shows a general increase in trust in the news: "Trust in the news in general increased in several countries and Portugal is no exception, with an increase of 5 pp. in relation to 2020 (from 56\% to 61\%)" (Cardoso et al., 2021, p. 10). The same study highlights the trust of the Portuguese towards local media stating that the data "reveals a very rich and very relevant consumption structure in a pandemic" and that this is due to a greater concern with the community in a period of confinement and the fact that globally "many Portuguese are of the opinion that the local and regional dimension is poorly represented in the media, in general" (Cardoso et al., 2021, p. 11).

The Portuguese local media-generated trust with the audiences and this can be verified by the demand for news about COVID-19, which accounted for $57.5 \%$ of the total items consulted. To a lesser extent, local politics, information about restaurants / shops and local economy followed (33.0\%, 32.5\% and 30.4\%, respectively).

This type of consumption by the audiences in relation to local media led the authors of the study to conclude that "local and regional media have a preponderant role in the news diet of the Portuguese" (Cardoso et al., 2021, p. 43). The report also concludes that "the attention given by the national media to the local dimension and to the reality that is close to the consumers is, in itself, proof that there is potential to explore in local, regional and proximity journalism, namely aspects that may contribute to greater relative proximity between the big brands and their audiences (Cardoso et al., 2021, p. 44).

Alongside this framework, the Portuguese local media seek to potentiate their presence on the Internet, as a way of emphasizing their social function as spaces of sharing, knowledge, and discussion on themes of public interest, as a privileged actor of the local dynamics that the local media represent.

In this sense, both the press and the Portuguese local radio have sought to be present on the Internet, including social networks, mobile platforms, and websites, meeting the challenges that arise due to a new media ecosystem dominated by digitalization. Although in a more modest scenario, Portugal has also seen the creation of several regional and local Web TV on the territory.

This new reality raises new issues for local media, as Jenkins and Jerónimo (2021, p. 14) state: “The implications of the digital transformation of local media are evident in the organizational structure and culture, leadership strategies, and roles and responsibilities of editors and reporters".

Another issue is related to its own scope, which is no longer conditioned by geography and territory and gains global contours. This new context brings more responsibilities to the local media that see their contents broadcasted on a larger scale and, on the other hand, reach new publics that, not being in the territory, have a bond with it (Garcia, 2012), as is the case of emigrant populations. Besides the geographical proximity, it is important to consider the existence of emotional, cultural, and even historical proximity. The local media assume thus a role of aggregator and connection with and between individuals that can greatly contribute to the dynamization and maintenance of collective consciousness and memory. The connection with the audiences may, in this context, be reinforced, not only through the dissemination of contents but also by opening space for online participation formats.

The advantages of online presence come up against, however, the organizational difficulties of several local media companies which have generated a "slower transition of the regional press to online formats" (Cardoso et al., 2018b, p. 10) trend that is also accompanied by the readers themselves who "continue to 
prefer the printed format of these publications, to the detriment still of the online format" (Cardoso et al., 2018b, p. 10).

Regarding radio, several authors, point out the high percentage of local radios that are present on the web. Bonixe (2017, p. 66) refers that "of the 35 Portuguese local radios that responded to the survey, only two do not have an online presence, either through a website or social networks". Portela (2011), on the other hand, identified in his study 178 local radios with streaming broadcast or with their own website. According to Piñero-Otero (2015), whom studied local radios in Galicia and northern Portugal, “(...) six of each ten local radio stations with conventional broadcasting have expanded their online presence through the creation of their website" (Piñero Otero, 2015).

But if quantitatively, the presence of Portuguese local radio stations is noteworthy for its high percentage values, the same cannot be said about the use of the tools and potentialities that online can offer to local broadcasters.

In this sense, Piñero-Otero (2015) underlines that local radios are still far from being designated as multimedia radios, since there are several web potentialities that are underused, such as comments or the possibility to intervene directly in the contents (Piñero-Otero, 2015). The author concludes that, despite the introduction of some tools, this has not generated more participatory radios, at least in the cases analyzed in Galicia and Northern Portugal. A scenario that may help explain the fact that in the Obercom study (Cardoso et al., 2018a, p. 88) the Portuguese local radio professionals surveyed had stated that if they received some kind of funding, that amount would be invested in improving their presence on websites and social media.

\section{METHODOLOGY}

Inspired by some of the theoretical aspects previously discussed, this article seeks to address the relationship that audiences keep with local media in Portugal. As such, the authors carried out several contacts with specific institutions to foster wider chances of getting people answering to the online survey ${ }^{1}$ we will describe later on. For instance, two different Portuguese Associations for Radio Broadcasting (APR and ARIC - in the Portuguese acronyms) were contacted. By providing them the online link of the survey, researchers expected that associates could answer the questions. However, this was not a very suitable approach due to limited answers collected. After this initial step, researchers autonomously contacted several local radio and newspapers asking them to post information about the survey, in social media and in websites, if so. Again, the level of answers did not increase as expected. So, researchers decided to post the online survey link in their personal social media accounts and this proved to be a turning point in the process.

Regardless these multiple actions, the authors believe that the main goal of the article was not compromised: reaching possible audiences, thus getting them to answer about their relationship with local media. However, it could seem widely vague to promote a research agenda featuring the simple definition of a relationship. This analysis involves the following specific categories; we defined as Research Questions (RQ), accordingly:

RQ 1 : how can we measure the consumption of local media?

RQ 2 : what kind of social perceptions can we identify towards the digital expansion of local media?

RQ 3 : what strategies are there to promote citizens' engagement in the local media scope?

RQ 4 : what kind of topics are most likely to be interesting for citizens and how do they feel about the media coverage towards their local town, from those media?

RQ 5 : how relevant was the pandemic for citizens to get involved with local media?

In order to answer these questions, two research techniques were used, which are related to one another. In one hand, following the classical understanding of Quivy and Campenhoudt (1995), authors used the questionnaire; however, this scientific tool is no stranger to criticism. Quivy and Campenhoudt (1995) suggested that this technique is suitable for the simple purpose of collecting large quantities of answers amongst participants; however, it is also stressed out that questionnaires lack on a deep understanding of complex questions, because the specific administration of such instrument does not provide chances to

${ }^{1}$ Available in http://www.lasics.uminho.pt/limesurvey/index.php/591135 


\section{Participants' Age}

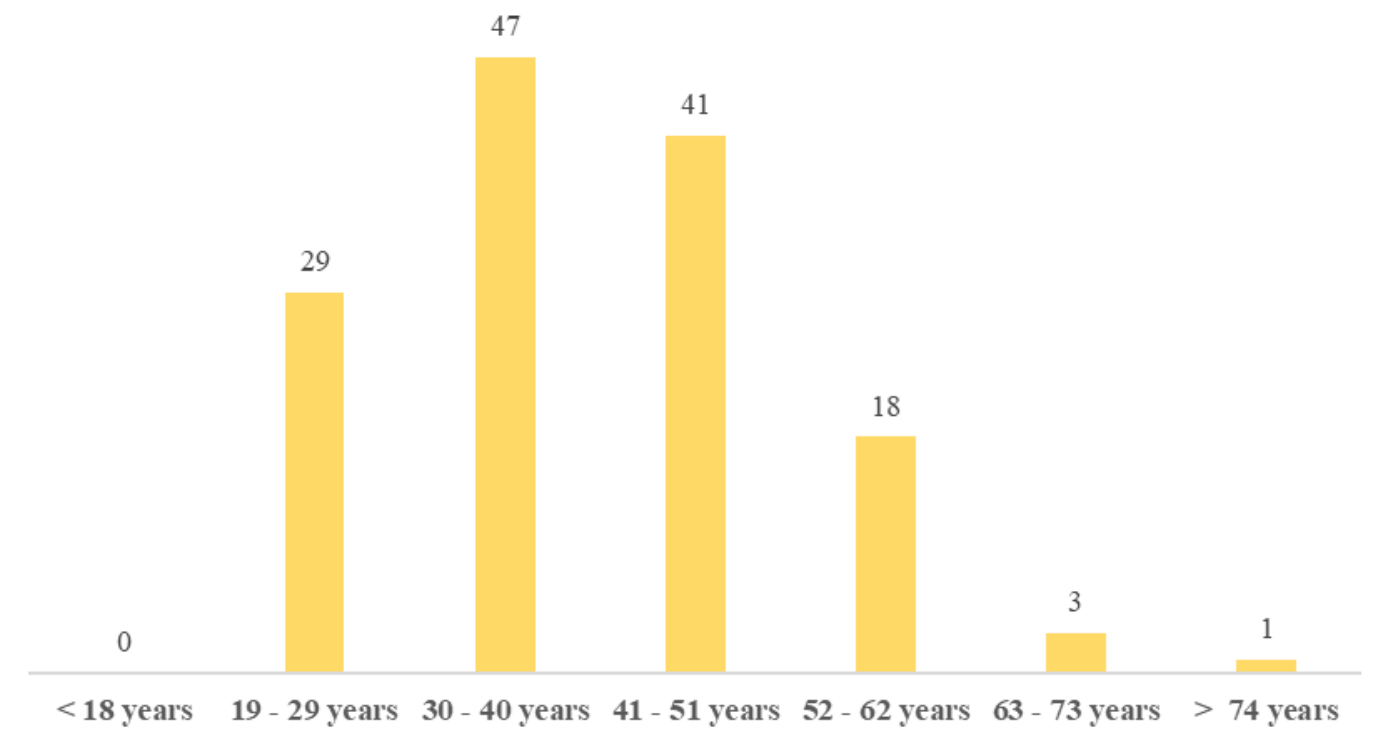

Figure 1. Participants' age distribution in the sample

engage with a specific discussion. In the particular case of the online surveys, we must also highlight that the level of answers "depends on the willingness of respondents to participate, and this is decreasing" (Dolnicar et al., 2013, p. 690), probably by some widespread use of this research technique (Kropf \& Blair, 2005). As we will describe later, some of the questions required further analysis, as respondents could answer using a plain text format, thus being able to add all suitable insights. A simple textual analysis was then carried out as to assess the main idea of the answer.

\section{Online Survey Administration and Sample}

Having in mind the above-mentioned research questions, the team identified the online survey as the most suitable scientific tool to engage with a potential wide portion of the population, thus defining a particular sample. Throughout multiple contacts, the online survey was then available to collect answers from $15^{\text {th }}$ April 2021 to $31^{\text {st }}$ May 2021. Social media was also a decisive trigger to boost answers, as the authors disseminate the link to several contacts.

Analysing the general data collected, 203 contacts engaged with the online survey. The majority of them completely answered to all questions; hence, we were able to validate 139 respondents. The remaining part - 64 - did not reach the end of the questionnaire and/or were not valid/credible answers. Therefore, the survey was $68.5 \%$ effective in its purpose of collecting reliable answers.

Before presenting the specific data, we should define this sample according to some social and demographic parameters. Most of the respondents are female (58.3\%), followed by $41.7 \%$ of men. Regarding age, Figure 1 presents the distribution in the sample.

Young adults seem to prevail in the sample, as the group between 30 to 40 years old dominate (47 out of 139), and 41-51 years old in a relevant presence (41 members). In terms of the district (region) belonging, where participants live in, Figure 2 also provides information towards it. 


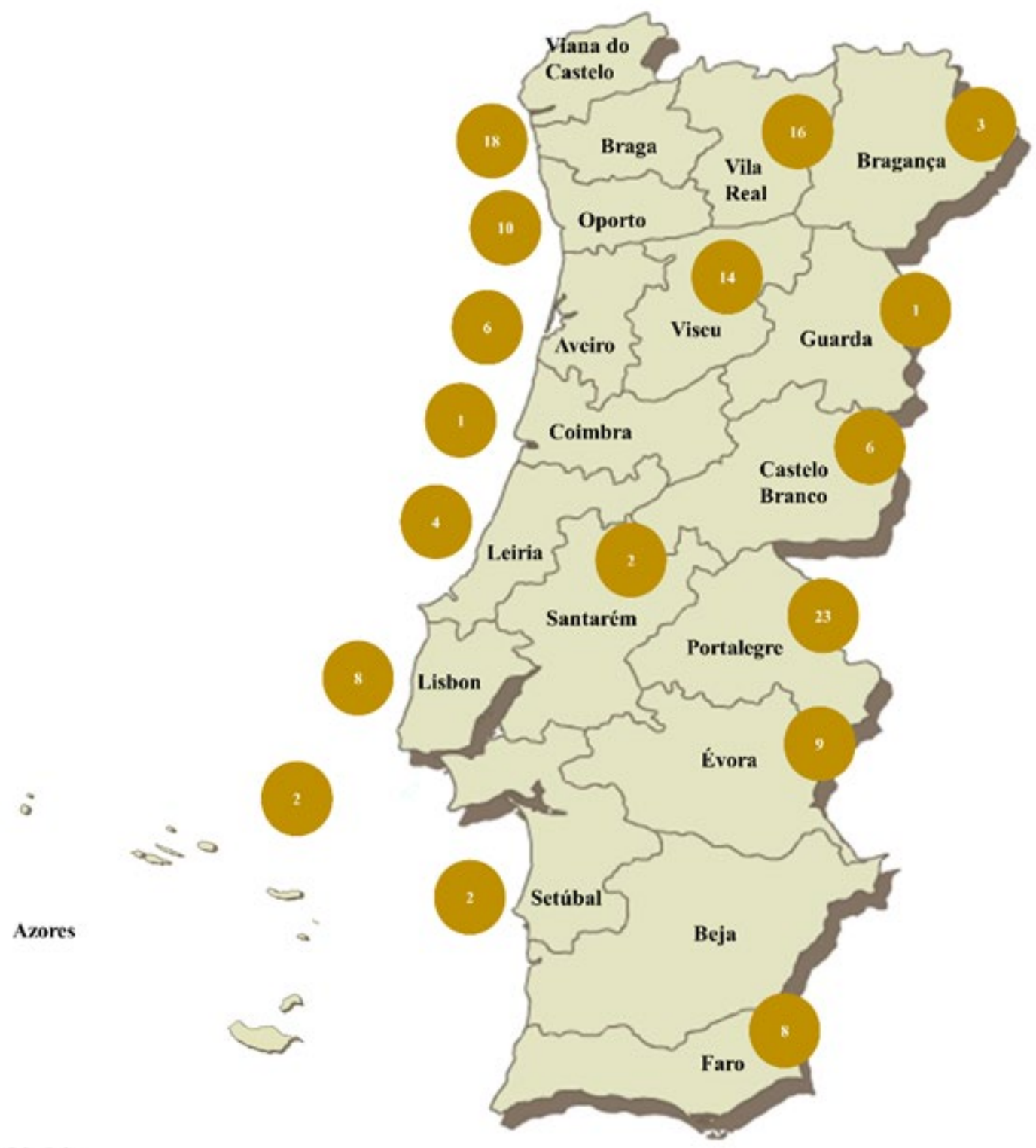

Figure 2. Participants' districts (regions) in the sample

Table 1. Participants professional status

\begin{tabular}{lc}
\hline Status & Frequency (\%) \\
\hline Active & $79.1 \%$ \\
Unemployed & $5.8 \%$ \\
Student & $12.9 \%$ \\
Retired & $2.2 \%$ \\
\hline Total & 139 \\
\hline
\end{tabular}

Although the authors made no effort to foster some diversity in the participants' district distribution, most of the administrative regions are present in the sample, excepting Beja, Viana do Castelo and the island of Madeira. Nevertheless, most of the participants live in the interior part of Portugal.

The last category of the social-demographic characterization of the sample includes the working status of the participants. Table 1 presents the general data in this regard.

Most of the participant are professionally active (almost $80 \%$ ) as students are the second most represented group (12.9\%). 
Table 2. Presence of different types of local media in the participants' districts

\begin{tabular}{lc}
\hline Type of media & Frequency (\%) \\
\hline Newspaper/Newsmagazine & $86.8 \%$ \\
Radio & $83.7 \%$ \\
Exclusive online newspaper & $39.5 \%$ \\
Exclusive online radio & $14 \%$ \\
Web TV & $27.9 \%$ \\
Does not know/Does not answer & $0.8 \%$ \\
Invalid & $0.8 \%$ \\
\hline
\end{tabular}

Table 3. General consumption of different types of local media in the sample

\begin{tabular}{lc}
\hline Type of media & Frequency (\%) \\
\hline Newspaper/Newsmagazine & 40.3 \\
Radio & 33.3 \\
Exclusive online newspaper & 16.3 \\
Exclusive online radio & 3.1 \\
Web TV & 2.3 \\
Does not know/does not answer & 2.3 \\
Invalid & 2.3 \\
\hline Total & $100 \%$ \\
\hline
\end{tabular}

Table 4. Consumption of exclusive online local media and FM radio within the sample

\begin{tabular}{lcc} 
& Frequency $(\%)$ & Frequency (\%) \\
& $\mathrm{N}=28$ & $\mathrm{~N}=43$ \\
\hline Temporal indicators & Exclusive online local media & Local FM radio \\
\hline Everyday & 60.7 & 51.2 \\
From 3 to 5 days a week & 21.4 & 23.3 \\
Once a week & 14.3 & 23.3 \\
Once a month & 0 & 0 \\
Does not know/Does not answer & 3.6 & 2.3 \\
\hline Total & $100 \%$ & $100 \%$ \\
\hline
\end{tabular}

In the next categories, the authors will analysed specific items of the general landscape of the local media bearing in mind the relationship of these mass media with citizens and audiences.

\section{Local media consumption levels}

As of 139 participants decided to answer the first questions of the sample, 129 confirmed that they lived in cities, broadly considering, where exists one local media, at least. Table 2 shows that there is some prevalence of local newspapers/newsmagazines and radios in those regions.

Participants were able to answer to multiple options. In doing so, newspapers/newsmagazines and radio, both in the traditional perspective, were the most selected ones, a situation that we may infer that mainstream media seem to be still widely relevant in the local media scope. The exclusively online media remained distant. When assessing a possible temporal consumption of these media, one might consider that traditional media, as posed before, still grasp a huge influence, when comparing to the online ones.

More than $70 \%$ of the participants claimed that newspapers, magazines and FM radio are the most consumed local media. Online media slightly overcome $20 \%$ of the preferences. Notwithstanding this general identification with these media, it was also important to address the exact temporal consumption of local media. Having in mind that individuals differently choose their preferences regarding different types of local media, as well as the circumstance that 123 participants correctly answering the following question, we had the following distribution: 28 measuring their media consumption habits in the online local scope; 52 in the press and 43 in radio. Tables 4 and 5 explain this important level of analysis.

Interestingly enough, all tables suggest that participants are widely aware of the media broadcasting/productions. The majority of the answers show a clear high frequency of consumption; more expressive in the local press media (71.1\%), comparing with local exclusive online media (60.7\%) and FM radio (51.2\%). These data may be able to underline the local media relevance for the audiences. 
Table 5. Consumption of local press media within the sample

\begin{tabular}{|c|c|}
\hline & $\begin{array}{c}\text { Frequency (\%) } \\
\mathrm{N}=52\end{array}$ \\
\hline Temporal indicators & Local press media \\
\hline Every time a new edition is published (daily, weekly, etc.) & 71.1 \\
\hline More randomly than that & 26.9 \\
\hline Does not know/Does not answer & 2 \\
\hline Total & $100 \%$ \\
\hline
\end{tabular}

Table 6. Reasons for the consumption of local media within the sample

\begin{tabular}{lc}
\hline Indicators & Frequency (\%) \\
\hline Family influences & 12.1 \\
Identification with the content & 29.8 \\
Seeking information & 90.3 \\
Participation in some programmes & 6.6 \\
No relevant reason & 8.1 \\
Does not know/Does not answer & 0.8 \\
Total & $100 \%$ \\
\hline
\end{tabular}

\section{Covid-19 pandemic and local media consumption levels}

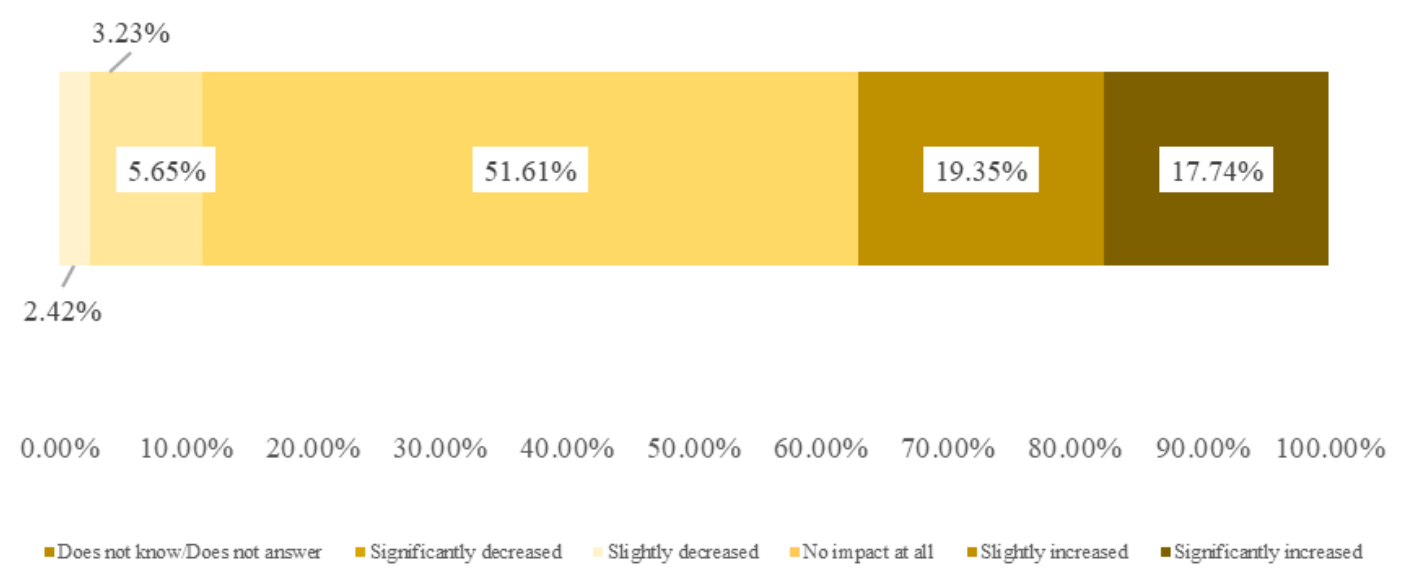

Figure 3. COVID-19 pandemic and local media consumption levels

The last two questions of this category - local media consumption levels - engage with a substantive approach towards these broadcasters. In Table 6, participants tried to identify (up to) three reasons that are somehow related with that specific level of consumption.

The thirst of information, regarding a municipality or a specific location, is the main reason for participants, highlighted in more than $90 \%$ of the cases. This survey also indicates that content is relevant for keeping audiences at the bay (29.8\%), as well as family influences (12.1\%).

Finally, participants were asked to determine whether the COVID-19 pandemic context have had any sort of effect in the consumption of local media. This survey was available after two general lockdowns in Portugal, during March-May 2020 and January-March 2021.

One could wonder if lockdown could increase audiences' willingness to follow these type of media, because a great part of the society was forced to stay indoors. Figure 3 states that the pandemic was not a decisive trigger to boost higher levels of local media consumption. Most of answers (51.61\%) claimed that no shifts were noted in this context. However, there is another possible interpretation coming for these data. With the exception of the majority (neutral), there is a significant part of the respondents whom defined their local media consumption affected by the two lockdowns, either "slightly" or "significantly": 37.09\%. Moving to the left side of Figure 3, both lockdowns only conducted to lower levels of local media consumption in $8 \%$ of 
Table 7. Digital scope presence of the local media for the participants

\begin{tabular}{lcccc}
\hline Digital scope & Yes & No & Does not know & Total \\
\hline Website & 87.9 & 5.6 & 6.5 & $100 \%$ \\
Facebook page & 96.0 & 0.8 & 3.2 & $100 \%$ \\
Twitter page & 16.9 & 39.5 & 43.5 & $100 \%$ \\
Instagram page & 29.0 & 31.5 & 39.5 & $100 \%$ \\
Soundcloud page & 8.1 & 46.0 & 46.0 & $100 \%$ \\
Mobile app & 12.1 & 47.6 & 40.3 & $100 \%$ \\
YouTube & 22.6 & 37.1 & 40.3 & $100 \%$ \\
Podcasts & 21.8 & 42.7 & 35.5 & $100 \%$ \\
\hline
\end{tabular}

Table 8. Satisfaction indicators across the digital platforms fostered by the local media

\begin{tabular}{lccc}
\hline & $\begin{array}{c}\text { Frequency } \\
\mathrm{N}=39\end{array}$ & $\begin{array}{c}\text { Frequency } \\
\mathrm{N}=82\end{array}$ & $\begin{array}{c}\text { Frequency } \\
\mathrm{N}=2\end{array}$ \\
\hline Satisfaction indicators & Website & Social media & Mobile apps \\
\hline Very positive & 5 & 19 & 0 \\
Positive & 23 & 32 & 1 \\
Neither positive, nor negative & 8 & 13 & 1 \\
Negative & 1 & 5 & 0 \\
Very negative & 2 & 9 & 0 \\
Does not know/Does not & 0 & 3 & 0 \\
Invalid & 0 & 1 & 0 \\
\hline Mean $(\mathrm{x})$ & 3.7 & 3.6 & 3.5 \\
\hline Median $(x)$ & 4 & 4 & 4
\end{tabular}

the respondents. As a result, we conclude that lockdowns were not absolutely decisive for audiences to be more active with local media, however, a very important part of them were definitely affected by the pandemic context in their specific relationship with these broadcasters, hence creating wider chances for people to consume more contend from these broadcasters.

\section{Local media digital scope perceptions}

Following previous discussions on the FM radio transition to the digital scope, including websites, social media and mobile apps, just to name a few possibilities (Piñeiro-Otero \& Ribeiro, 2015), the authors decided to evaluate audiences' perceptions towards the extension of local media into such technological domains, thus participating 124 individuals. Table 7 tries to identify the recognition of participants towards the digital spaces of the most preferable local media the contestants previously indicated.

After collecting the data, authors wondered about the troubling aspects within this question. Although this type of scientific approach should trust in data, the researchers acknowledge that probably it is very hard for the audiences to indicate whether a specific media has a Twitter page, a mobile app or podcasts, even though a "does not know" possible answer was added. Notwithstanding this cautious note, websites, Facebook and Twitter pages are the most recognizable platforms, on the contrary as YouTube, mobile apps and podcasts. Sound-based social media Soundcloud suggests a great deal of uncertainty and doubts amongst users.

The next question addressed the digital platforms the participants most constantly access to. Facebook dominates by far with roughly $60 \%$ of the choices, distantly followed by local media websites (31.5\%) and Instagram pages (5.6\%). Afterwards, according to their preferences and routines, participants ranked the local media digital efforts in those platforms, as suggested by Table 8.

Researchers coded this variable using an ordinal standard, from 1 point in "very negative" to 5 in "very positive" indicators. Hence, participants seem satisfied with local media efforts to communicate across all platforms. Statistical instruments, such as mean and median, also present values close to a positive (4) indicator. Negative perceptions were not numerically significantly.

The last set of questions in this category of analysis seeks to explore participants' willingness to actively participate in the local media scope. Using Ribeiro's approach (2020) of active participation in the media, rooted in Wasko and Mosco (1992), just to name a few theoretical inspiration in this wide field of studies, individuals answered if they have already commented, shared posts or participated in contests in the those 
Table 9. Interaction strategies with local media

\begin{tabular}{lc}
\hline Interactive strategies & Frequency (\%) \\
\hline Commenting in social media & 34.9 \\
Commenting in the website & 17.2 \\
Proposing ideas for news & 46.9 \\
Proposing ideas for entertainment & 23.4 \\
Criticising contents & 20.3 \\
Participating in live programmes & 25 \\
Does not answer/ Does not know & 3.1 \\
Other & 11 \\
\hline
\end{tabular}

Table 10. Local topics most access by the participants across media

\begin{tabular}{|c|c|c|c|c|c|}
\hline & & & Topics & & \\
\hline Platforms & Sports & Society & Culture & Economics & Politics \\
\hline Printed media & 9.4 & 20.9 & 15.8 & 20.9 & 26.6 \\
\hline Radio (FM or online) & 10.8 & 19.4 & 12.9 & 13.7 & 18.0 \\
\hline Web TV & 2.2 & 0.7 & 1.4 & 1.4 & 1.4 \\
\hline Social media in general & 36.0 & 38.8 & 47.5 & 28.8 & 35.3 \\
\hline National mainstream media & 12.2 & 14.4 & 17.3 & 21.6 & 7.2 \\
\hline Other & 2.9 & 3.6 & 4.3 & 4.3 & 7.2 \\
\hline I do not follow this topic & 26.6 & 2.2 & 0.7 & 9.4 & 4.3 \\
\hline
\end{tabular}

local media broadcasters. Firstly, the majority of the participants have participated in such context $(51,6 \%)$, but only leading with a small margin, though (47.7\%).

In order to understand such level of interaction, participants indicated what kind of action were responsible for as to be involved with local media. Table 9 states those interactive strategies.

As participation is widely regarded as a "floating signifier" (Arnstein, 1969), thus involving a whole complex of strategies, participants in the survey could answer as many as possible. It is somehow impressive that almost half of the individuals (46.9\%) confirmed that they suggested ideas for possible news for the local media journalists. This important data is distant from commenting in social media (34.9\%), proposing ideas for entertainment (23.4\%) and online commenting (17.2\%). Suggesting topics for a journalistic approach is arguably a more complex strategy which may deliver different interpretations: citizens feel unattached to the journalistic work of local media; political influences; low quality in local media journalism. Criticism also gathers an important part of the participation processes, in more than $20 \%$ of the cases.

\section{General aspects in the citizens' relationship with local media information}

The third - and final - level of analysis of the survey seeks to explore the issues within society that typically individuals follow the most. From sports to culture and politics, including others related to a local society, 139 individuals indicated what kind of topics they seek the most across the platforms. Table 10 organizes the data in this regard.

Common sense states that Portuguese people are constantly looking for sports news, namely football. Nonetheless, the "sports" category was the one participants do not follow the most (26.6\%). Arguably in some locations sports is not particularly relevant. Having in mind all the issues that are related to the a specific localness, Table 10 clearly states that social media, in general, is the most preferable source to be informed about sports, society, culture, economics and politics; to sum up, in all covered ones. National mainstream media is also a very frequent source of news in those areas, very important in the economics sector (21.6\%). So, excluding the predominance of social media in general to find news of a local context, participants suggested that: national mainstream media are frequently accessed to get local sports news (12.2\%), culture (17.3\%) and economics (21.6\%); printed media for society news (20.9\%) and politics (26.6\%).

The final question of the survey tries to collect a general evaluation of participants towards their satisfaction towards the ability of local media to inform about general topics of a community living in a small location (Figure 4). 


\section{Satisfaction with local media news coverage}

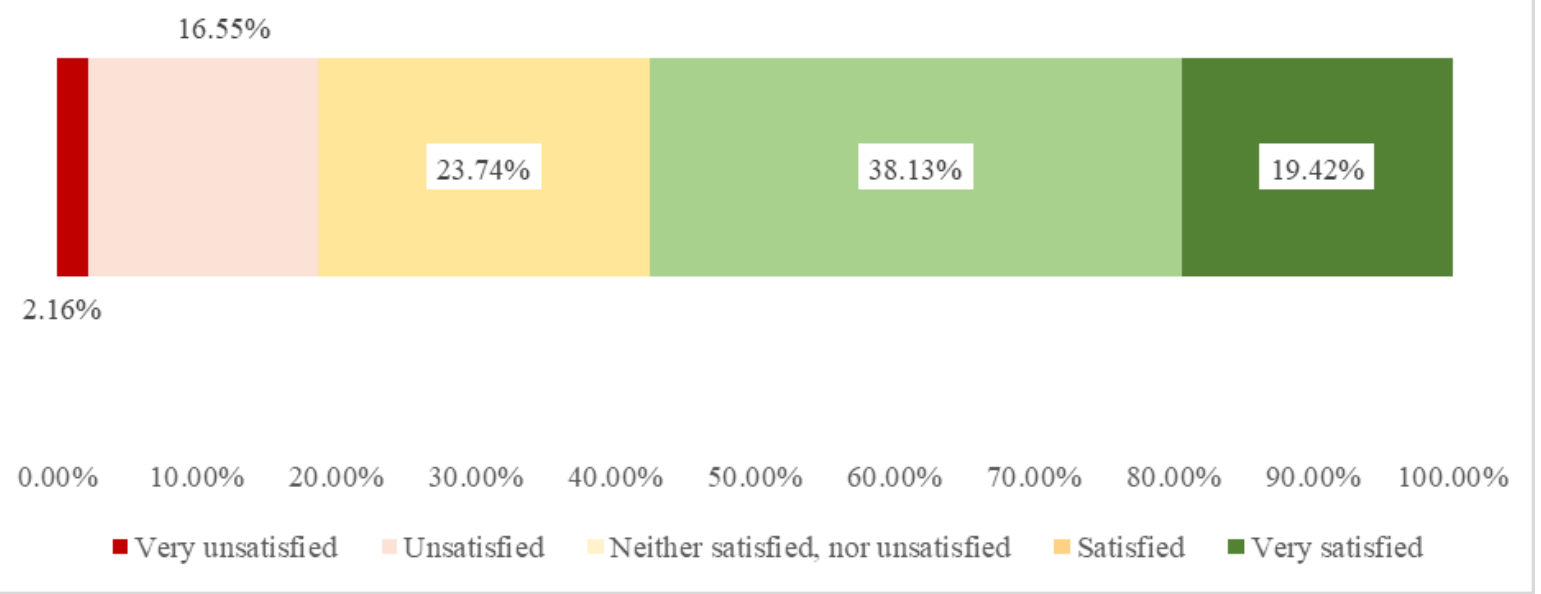

Figure 4. Levels of satisfaction towards the local media ability to cover local topics

A relevant part of the sample is neutral to the proposed evaluation (23.8\%). However, this is not the most important insight of the question itself. Most of the 139 participants seem to be satisfied (38.1\%) and very satisfied (19.4\%) with the local journalists work covering topics occurring in this scope. This positive assessment is actually $57.5 \%$ of the sample, comparing with the negative evaluation, representing only $18.8 \%$ of the distribution of answers.

\section{FINAL REMARKS}

As described earlier on, the implementation of this survey was no strange to several constraints. In future approaches, researchers should consider other effective strategies to interact with audiences of local media. Probably, other scientific tools could be observed, as well. Focus group and interviews could add important insights to the ones provided by this survey, which definitely present interesting data, but further analysis and explanations are missing. This is one of the reasons why the authors stand for possible methodological links towards this type of studies. Regardless all the (important) technicalities in the sample definition, this survey collects data in a specific field of studies that often lack from interest in the academia.

Globally addressing this sample of 139 individuals, whom 129 fully responded to the local media questions, a gender balanced configuration was found (mostly women, in a 58\%-42\% proportion), in an adult wide landscape (from 30 to 50 years old), generally employed (80\%). This sample also indicates that the consumption of traditional media (Research Question 1), in the local scope, are still predominant (slightly more than 70\%), when comparing to the online possibilities regarded. The participants acknowledge the need of constant information towards the local they live in, although identification with a specific media and the family influences both display important roles on the justification to follow/consume a local specific media. This research also states that local media levels of consumption were not decisively affected by the COVID-19 pandemic (Research Question 5), although a very important 37\% of the respondents confirmed increased interest in following these media.

In the digital framework of this online survey (Research Question 2), the team must address some important notes as well. Individuals typically recognize websites and social media platforms, especially Facebook rather than Instagram or Twitter, as circuits of information and communication of local media broadcasters. Strangely enough, audiovisual possibilities such as Soundcloud, YouTube or podcasts seem neglected for the sample. Participants also stressed their satisfaction towards the local media activity in those spaces and a significant part of the sample (64 out of 129) confirmed higher levels of interaction with these media (Research Question 3), mainly suggesting ideas or topics for journalists to cover local matters. After analysing the overall data, researchers missed a deeper approach on the specificities of satisfaction: what is 
most valued by audiences in content? what sort of issues are proposed for journalistic to work on? for the ones whom negatively reacted to the digital platforms' activity, what kind of reasons are there to be explored? In terms of participations, authors also acknowledge that probably it would be useful to measure participation dynamics.

Finally, as participants seemed pleased with the news coverage fostered by the local media (Research Question 4), it is clear that social media accounts in general are important sources of information for audiences. Journalism is arguably a guardian of accurate information and social media often demonstrate a difficult relationship with reliable and trustworthy data. In the local context, this is actually very important, as some regions in Portugal do not have a registered local media and, as such, information is compromised.

Directly addressing this special issue mojo, this article suggests plenty possibilities to understand why the audiences may be very important for the local media institutions. Following one of the most expressive data, a very active part of the sample undoubtedly considered that local journalists are not fully exploring the potential of covering all the important aspects in these communities. Probably there is a lack of representation in the local media sphere, thus neglecting the relevance or the public salience of several matters. This is a very critical point in this survey, which raises the decisive trigger of citizens' awareness on the need of public debate. Maybe local journalism is not doing its job properly. Moreover, this exploratory study indicates that audiences do need the journalistic activity to learn from several aspects in the community. Portugal is not a geographically large country, but disinformation thrives in the absence of interested communities and groups and the effectiveness of information provided by journalists. Relying on social media the role of informing these citizens is dangerous, as it has been widely reported that large companies such as Facebook, Twitter, Google, etc., do invest in commercial approaches rather that civic-based purposes. In the Portuguese case, citizens cannot wait any longer for more active and dynamic media to learn what is happening next door. Qualify life is more than physical infrastructures.

Author contributions: All authors were involved in concept, design, collection of data, interpretation, writing, and critically revising the article. All authors approve final version of the article.

Funding: The authors received no financial support for the research and/or authorship of this article.

Declaration of interest: Authors declare no competing interest.

Data availability: Data generated or analysed during this study are available from the authors on request.

\section{REFERENCES}

Arnstein, S (1969). A Ladder of Citizen Participation. Journal of the American Institute of Planners, 35(4), $216-224$. https://doi.org/10.1080/01944366908977225

Bonixe, L. (2017). As rádios locais portuguesas na transição para a Internet [Portuguese local radio stations in the transition to the Internet]. In P. Jerónimo (Ed.), Media e Jornalismo de Proximidade na Era Digital (pp. 47-86). http://www.labcom-ifp.ubi.pt/book/298

Bonixe, L. (2021). Resiliência e crise - a rádio portuguesa na pandemia do novo coronavírus [Resilience and crisis - Portuguese radio in the new coronavirus pandemic]. Estudos em Comunicação, 32, 69-93. https://doi.org/10.25768/21.04.03.32.04

Branco, S. (Setubalense, 2020, May 20). Na Imprensa regional vai um país [In the regional press there is a country]. O Setubalense. https://www.osetubalense.com/opiniao/2020/05/20/na-imprensa-regional-vaium-pais/

Cardoso, G., Baldi, V., Quintanilha, T., Paisana, M. \& Pais, P. (2018b). Jornais regionais - A análise de perfis de utilização. Actividade, desafios e políticas públicas para o sector [Regional newspapers - Analysis of usage profiles. Activity, challenges and public policies for the sector]. Observatório da Comunicação. https://obercom.pt/wp-content/uploads/2018/04/CIUL-CV-OberCom2018-Jornais-regionaisAna\%CC\%81lise-de-perfis-de-utilizac\%CC\%A7a\%CC\%83o.pdf

Cardoso, G., Baldi, V., Quintanilha, T., Paisana, M., \& Pais, P. (2018a). As Rádios Locais em Portugal Caracterização, tendências e futuros [Local Radios in Portugal - Characterization, trends and futures]. https://obercom.pt/wp-content/uploads/2018/04/CIUL-CV-OberCom2018-Ra\%CC\%81dios-LocaisCaracterizac\%CC\%A7a\%CC\%83o-tende\%CC\%82ncias-e-futuros-.pdf 
Cardoso, G., Paisana, M., \& Martinho, P. A. (2021). Digital news report Portugal 2021. https://obercom.pt/wpcontent/uploads/2021/06/DNR_PT_2021_final.pdf

Carvalho, A., Faustino, P. \& Martins, M. (2010). Estudo de Impacto dos Incentivos diretos concebidos pelo Estado aos órgãos de comunicação social regional e local [Impact Study of Direct Incentives Designed by the State for Regional and Local Media]. Media XXI.

Castells, M. (2003). O Poder da Identidade [The Power of Identity]. Calouste Gulbenkian.

Dolnicar, S., Grün, B., \& Yanamandram, V. (2013). Dynamic, interactive survey questions can increase survey data quality. Journal of Travel \& Tourism Marketing, 30(7), 690-699. https://doi.org/10.1080/10548408.2013.827546

ERC (2020). Relatório de Avaliação do impacto da pandemia de COVID-19 sobre o setor da comunicação social em Portugal [COVID-19 pandemic impact assessment report on the media sector in Portugal]. https://www.flipsnack.com/ERCpt/avalia-o-do-impacto-da-pandemia-COVID-19-no-setor-dosmedia/full-view.html

García, X. (2012). Ciberperiodismo en la proximidad [Cyberjournalism in proximity]. Comunicación Social ediciones y publicaciones.

Jenkins, J., \& Graves, L. (2019). Case studies in collaborative local journalism. https://reutersinstitute.politics.ox.ac.uk/our-research/case-studies-collaborative-local-journalism

Jenkins, J., \& Jerónimo, P. (2021). Changing the beat? Local online newsmaking in Finland, France, Germany, Portugal, and the U.K. Journalism Practice. Published online: 26 Apr 2021. https://doi.org/10.1080/17512786.2021.1913626

Jenkins, J., \& Nielsen, R. (2018). The digital transition of local news. https://reutersinstitute.politics.ox.ac.uk/ourresearch/digital-transition-local-news

Jerónimo, P., Morais, R., \& Correia, J.C. (2020). Jornalismo na Região Centro- trabalho, tecnologia e negócio [Journalism in the Central Region - work, technology and business]. Labcom. http://www.labcom.ubi.pt/ficheiros/202105211357202011_jornalismoregiaocentro_rmoraispjeronimoj ccorreia.pdf

Kropf, M. E., \& Blair, J. (2005). Eliciting survey cooperation: Incentives, self-interest, and norms of cooperation. Evaluation Review, 29(6), 559-575. https://doi.org/10.1177/0193841X05278770

Piñeiro-Otero, T. (2015). La mediamorfosis de la radio local. Una perspectiva desde el contexto de la Eurorregión Galicia - Norte de Portugal [The mediamorphosis of local radio. A perspective from the context of the Euroregion Galicia - North of Portugal]. Quaderns del CAC, 41, 35-45. https://www.researchgate.net/publication/281112829

Piñeiro-Otero, T., \& Ribeiro, F. (2015). Radio mobility in the digital era: interactivity, participation and content share possibilities in Iberian broadcasters. Comunicação e Sociedade, 28, 291-308. https://doi.org/10.17231/comsoc.28(2015).2282

Portela, P. (2011). Rádio na Internet em Portugal - A abertura à participação num meio em mudança [Internet Radio in Portugal - Opening up to participation in a changing environment]. Edições Húmus.

Quivy, R., \& Campenhoudt, L. (1992). Manual de investigação em ciências sociais [Social science research manual]. Gradiva.

Ribeiro, F. (2020). Book review "Images of immigrants and refugees in Western Europe. Media representations, public opinion, and refugees experiences". Comunicação e Sociedade, 38, 257-264. https://doi.org/10.17231/comsoc.38(2020).2559

Wasko, J., \& Mosco, V. (1992). Democratic communications in the information age. Garamond Press \& Ablex.

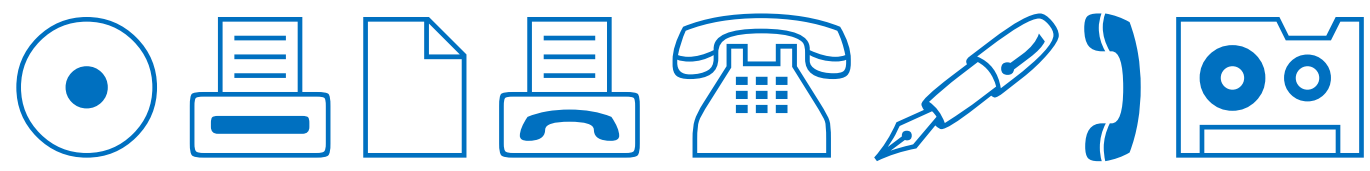

